\title{
Advanced glycation end products potentiate citrated plasma-evoked oxidative and inflammatory reactions in endothelial cells by up-regulating protease-activated receptor-1 expression
}

\author{
Yuji Ishibashi', Takanori Matsui ${ }^{1}$, Seiji Ueda ${ }^{2}$, Kei Fukami ${ }^{2}$ and Sho-ichi Yamagishi ${ }^{1 *}$
}

\begin{abstract}
Advanced glycation end products (AGEs) and receptor RAGE interaction contribute to endothelial cell damage in diabetes. Several thrombogenic abnormalities are also involved in diabetic vascular complications. However, the pathological role of thrombin and protease-activated receptor-1 (PAR-1) system in AGE-induced endothelial cell (EC) damage remains unclear. In this study, we investigated the effects of rivaroxaban, an inhibitor of factor Xa on 3\% citrated human plasma-evoked reactive oxygen species (ROS) generation and RAGE, monocyte chemoattractant protein-1 (MCP-1) and intercellular adhesion molecule-1 (ICAM-1) gene expression in AGE-exposed ECs. We further examined whether FR171113, an inhibitor of PAR-1 blocked the plasma-induced EC damage and if AGEs increased PAR-1 expression in ECs. Human citrated plasma stimulated ROS generation and RAGE, MCP-1 and ICAM-1 expression in ECs, all of which were potentiated by the treatment with AGEs. Rivaroxaban or FR171113 significantly inhibited these derangements in plasma- or plasma plus AGE-exposed ECs. Moreover, AGEs significantly increased the PAR-1 levels in ECs. The present study suggests that citrated plasma could induce oxidative and inflammatory reactions in ECs via the activation of thrombin-PAR-1 system and that AGEs could potentiate the plasma-evoked EC damages via up-regulation of PAR-1. Blockade of the crosstalk between AGE-RAGE axis and coagulation system by rivaroxaban might be a novel therapeutic target for thromboembolic disorders in diabetes.
\end{abstract}

Keywords: AGEs, RAGE, Endothelial cells, Diabetes, PAR-1, Rivaroxaban

\section{Background}

Sugars, including glucose, fructose and trioses can react non-enzymatically with the amino groups of proteins, lipids and nucleic acids to form reversible Schiff bases, and then Amadori products [1-3]. These early glycation products undergo further complex reactions such as rearrangement, dehydration and condensation to become irreversibly cross-linked, heterogeneous fluorescent derivatives called "advanced glycation end products (AGEs)" [1-3]. The formation and accumulation of AGEs in various tissues have been known to progress at a physiological aging and at an accelerated rate under

\footnotetext{
* Correspondence: shoichi@med.kurume-u.ac.jp

'Department of Pathophysiology and Therapeutics of Diabetic Vascular Complications, Kurume University School of Medicine, 67 Asahi-machi, Kurume 830-0011, Japan

Full list of author information is available at the end of the article
}

hyperglycemic conditions [1-3]. There is an accumulating body of evidence that engagement of receptor for AGEs (RAGE) with the ligand AGEs elicits oxidative stress generation and resultantly evokes inflammatory and thrombogenic reactions in endothelial cells (ECs), thereby playing a central role in vascular complications in diabetes [4-9].

Several types of thrombogenic abnormalities have also contributed to the development and progression of vascular damage and thromboembolic disorders in patients with diabetes [10-13]. AGEs not only inhibit prostacyclin production in ECs through the interaction with RAGE, but also induce plasminogen activator inhibitor-1, thus promoting platelet aggregation and fibrin stabilization, thus resulting in a predisposition to thrombogenesis in diabetes $[10,14]$. Furthermore, the AGE-RAGE interaction stimulates tissue factor expression in ECs, being 
implicated in hypercoagulability in diabetes as well [15]. However, the pathological role of thrombin and proteaseactivated receptor-1 (PAR-1) system in AGE-induced EC damage remains unclear. Therefore, in this study, we investigated the effects of rivaroxaban, an inhibitor of factor $\mathrm{Xa}$ on 3\% citrated human plasma-evoked reactive oxygen species (ROS) generation and RAGE, monocyte chemoattractant protein-1 (MCP-1) and intercellular adhesion molecule-1 (ICAM-1) gene expression in AGE-exposed human umbilical vein ECs (HUVECs). We further examined whether FR171113, an inhibitor of PAR-1 blocked the plasma-induced EC damage and if AGEs increased the PAR-1 expression in HUVECs.

\section{Methods}

\section{Materials}

An inhibitor of $\mathrm{Xa}$, rivaroxaban was purchased from Tronto Research Chemicals Inc. (Toronto, Canada). Cit rated human plasma from Tennessee Blood Sciences, Memphis, TN, USA. Bovine serum albumin (BSA) (essentially fatty acid free and essentially globulin free, lyophilized powder), diphenylene iodonium (DPI) and a blocker of PAR-1, FR171113 were from Sigma (St. Louis, MO, USA). D-glyceraldehyde was purchased from Nakalai Tesque (Kyoto, Japan).

\section{Preparation of AGE-BSA}

AGE-BSA was prepared as described previously [16]. In brief, BSA $(25 \mathrm{mg} / \mathrm{ml})$ was incubated under sterile conditions with $0.1 \mathrm{M}$ glyceraldehyde in $0.2 \mathrm{M} \mathrm{NaPO}_{4}$ buffer ( $\mathrm{pH} 7.4$ ) for 7 days. Then unincorporated sugars were removed by PD-10 column chromatography and dialysis against phosphate-buffered saline. Control non-glycated BSA was incubated in the same conditions except for the absence of reducing sugars. Preparations were tested for

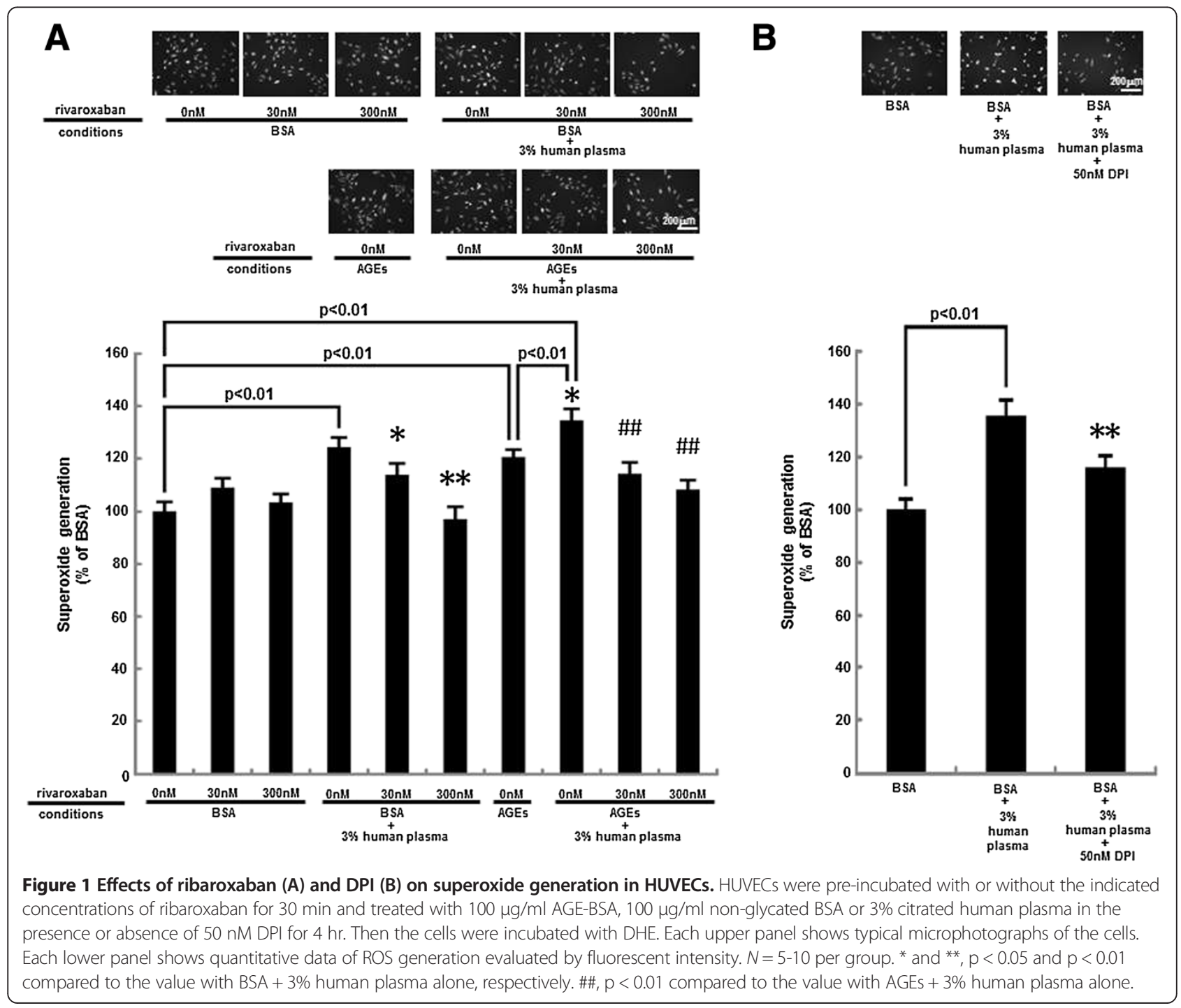




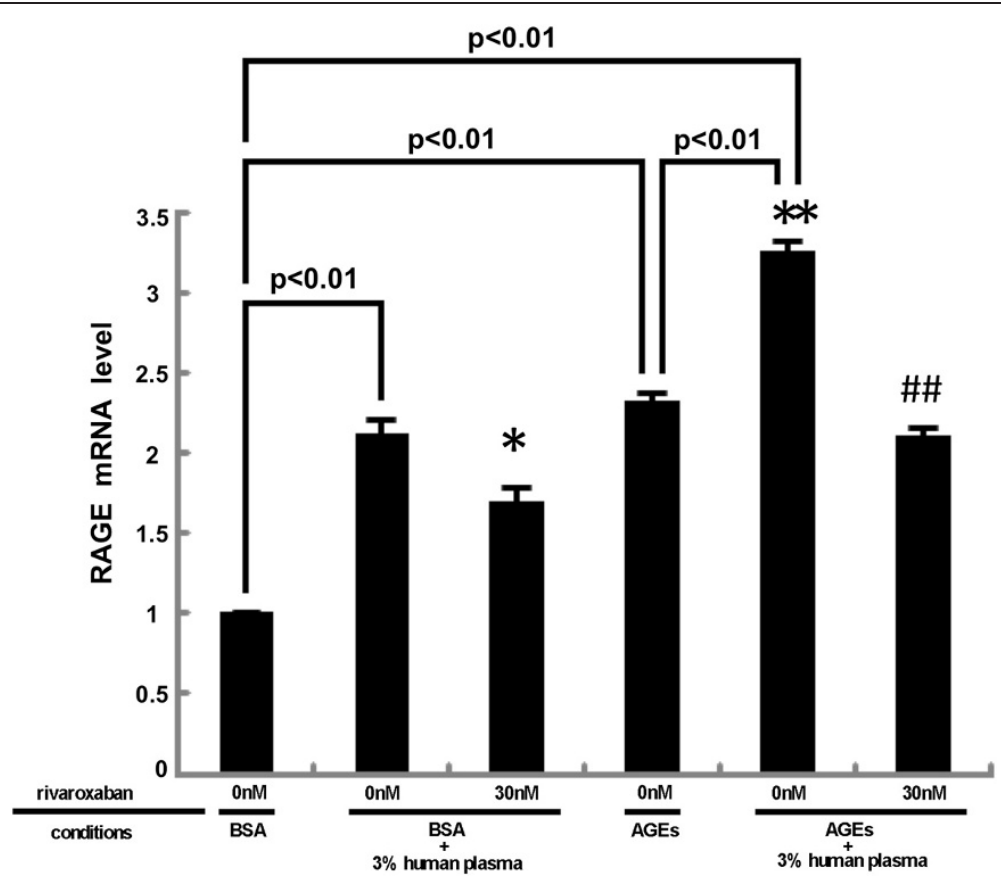

Figure 2 Effects of ribaroxaban on RAGE gene expression in HUVECs. HUVECs were pre-incubated with or without the indicated concentrations of ribaroxaban for $30 \mathrm{~min}$ and treated with $100 \mathrm{\mu g} / \mathrm{ml} \mathrm{AGE-BSA,} 100 \mathrm{\mu g} / \mathrm{ml}$ non-glycated BSA or 3\% citrated human plasma for 4 hr. Then total RNAs were transcribed and amplified by real-time PCR. Data were normalized by the intensity of $\beta$-actin mRNA-derived signals and then related to the value obtained with BSA alone. $N=3$ per group. ${ }^{*}$ and ${ }^{*}, p<0.05$ and $p<0.01$ compared to the value with $B S A+3 \%$ human plasma alone, respectively. $\# \#, p<0.01$ compared to the value with AGEs $+3 \%$ human plasma alone.

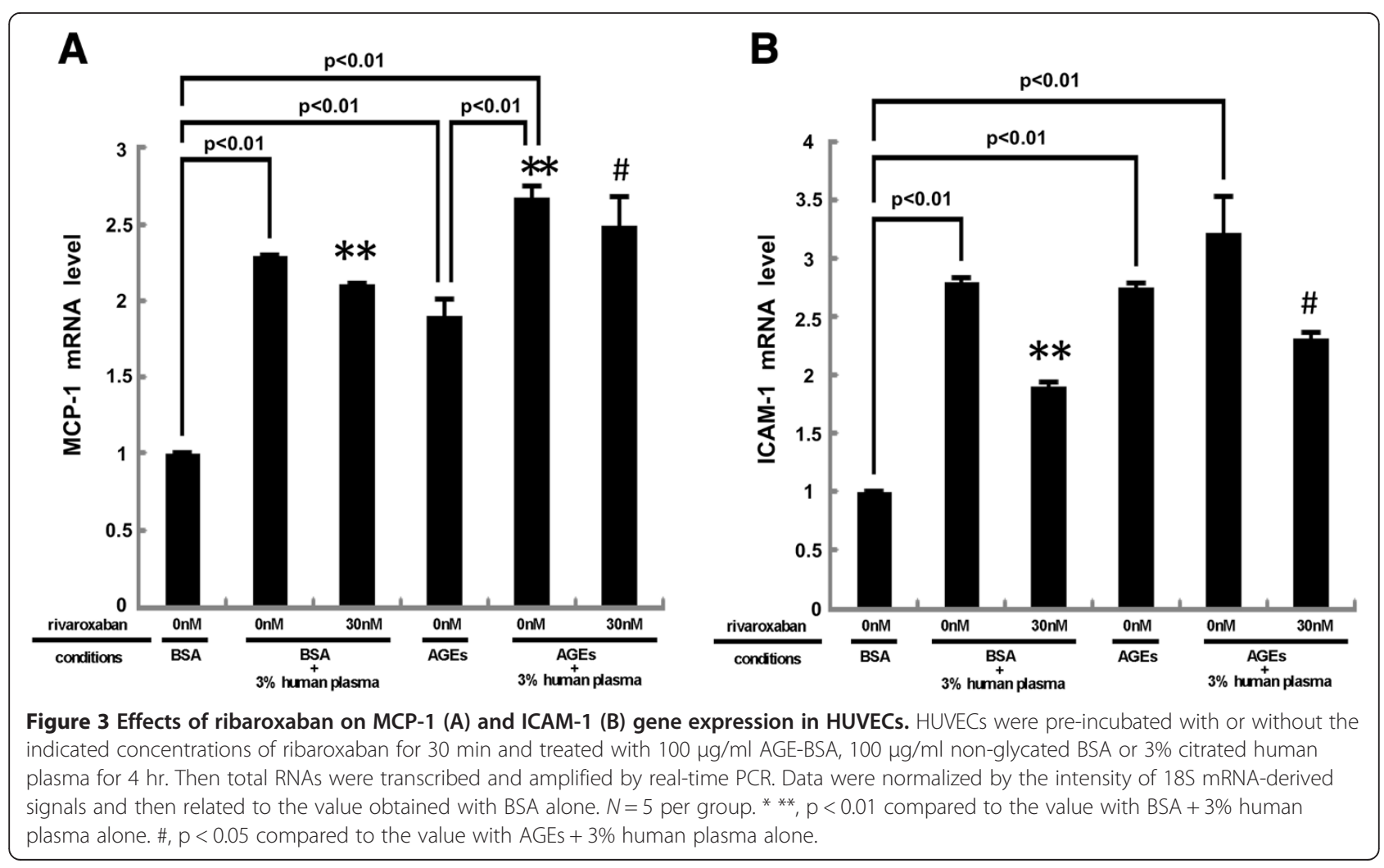


endotoxin using Endospecy ES-20S system (Seikagaku Co., Tokyo, Japan); no endotoxin was detectable.

\section{Cells}

HUVECs obtained from Lonza Group Ltd. (Basel, Switzerland) were cultured in endothelial basal medium supplemented with $2 \%$ fetal bovine serum, $0.4 \%$ bovine brain extracts, $10 \mathrm{ng} / \mathrm{ml}$ human epidermal growth factor and $1 \mu \mathrm{g} / \mathrm{ml}$ hydrocortisone according to the supplier's instructions. Rivaroxaban or AGE treatment was carried out in a medium lacking fetal bovine serum, epidermal growth factor and hydrocortisone.

\section{Dihydroethidium (DHE) staining}

HUVECs were pre-incubated with or without the indicated concentrations of rivaroxaban for $30 \mathrm{~min}$ and treated with $100 \mu \mathrm{g} / \mathrm{ml}$ AGE-BSA, $100 \mu \mathrm{g} / \mathrm{ml}$ nonglycated BSA or $3 \%$ citrated human plasma in the presence or absence of $50 \mathrm{nM}$ DPI, $1 \mathrm{mM}$ FR171113 for $4 \mathrm{hr}$. Then the cells were incubated with phenol red free Dulbecco's Modified Eagle Medium containing $3 \mu \mathrm{M}$ DHE (Molecular Probes Inc., Eugene, OR, USA). After 15 minutes, the cells were imaged under a laser-scanning confocal microscope. Superoxide generation was evaluated by intensity of DHE staining. The intensity was analyzed by microcomputer-assisted NIH image.

\section{Real-time reverse transcription-polymerase chain reactions (RT-PCR)}

HUVECs were pre-incubated with or without the indicated concentrations of rivaroxaban for $30 \mathrm{~min}$ and treated with $100 \mu \mathrm{g} / \mathrm{ml} \mathrm{AGE-BSA,} 100 \mu \mathrm{g} / \mathrm{ml}$ non-glycated BSA or $3 \%$ citrated human plasma in the presence or absence of $1 \mathrm{mM}$ FR171113 for $4 \mathrm{hr}$. Then total RNA was extracted with RNAqueous-4PCR kit (Ambion Inc., Austin, TX, USA) according to the manufacturer's instructions. Quantitative

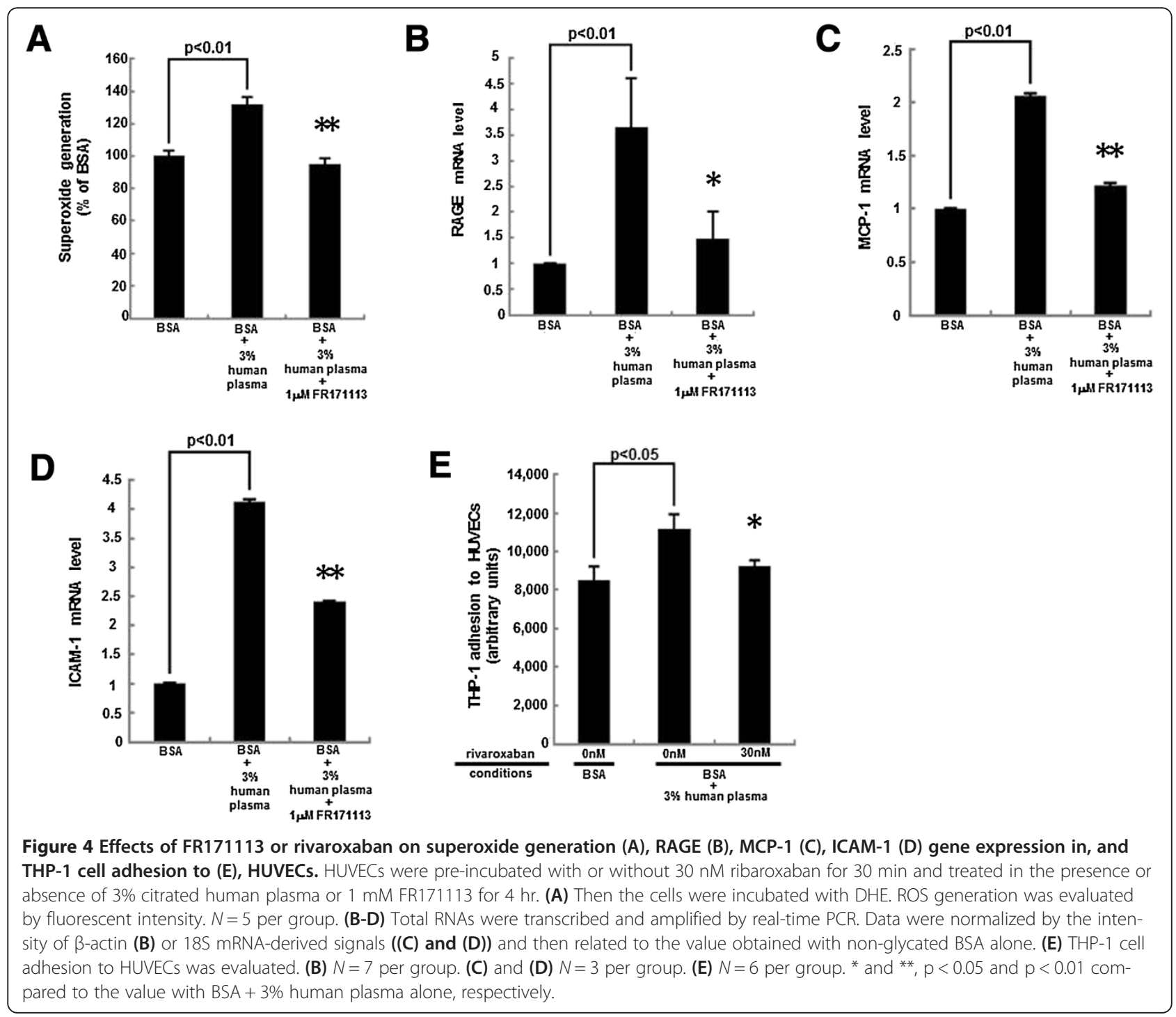


real-time RT-PCR was performed using Assay-on-Demand and TaqMan 5 fluorogenic nuclease chemistry (Applied Biosystems, Foster city, CA, USA) according to the supplier's recommendation. IDs of primers for human RAGE, MCP-1, ICAM-1, $\beta$-actin and $18 \mathrm{~S}$ gene were $\mathrm{Hs} 00$ 153957_m1, Hs00234140_m1, Hs00164932_m1, Hs99999 903_m1, and Hs99999901_s1, respectively.

\section{Assay of THP-1 cell adhesion to HUVECs}

Human THP-1 monocytic leukemia cells (American Type Culture Collection, Manassas, VA, USA) were maintained in RPMI 1640 medium supplemented with 1\% GultaMAX (Life Technologies Corporation, Carlsbad, CA, USA) and $1 \%$ fetal bovine serum (NICHIREI BIOSCIENCES INC, Tokyo, Japan). THP-1 cells were labeled with $3 \mathrm{mM}$ BCECF-AM (Dojindo, Kumamoto, Japan) at $37^{\circ} \mathrm{C}$ for $30 \mathrm{~min}$ according to the supplier's recommendation. THP-1 cell adhesion to HUVECs was assayed according to the method described previously [17]. Briefly, HUVECs were treated with or without $100 \mu \mathrm{g} / \mathrm{ml}$ non-glycated BSA or $3 \%$ citrated human plasma in the presence or absence of $30 \mathrm{nM}$ rivaroxaban for $4 \mathrm{hr}$, and then incubated with BCECF-AM-labeled THP-1 cells for $4 \mathrm{hr}$. After the incubation, nonadherent THP-1 cells were removed by washing the HUVECs gently. Fluorescent intensities of the adherent THP-1 cells were measured.

\section{Western blot analysis}

HUVECs were treated with or without $100 \mu \mathrm{g} / \mathrm{ml}$ AGEBSA or $100 \mu \mathrm{g} / \mathrm{ml}$ non-glycated BSA for $4 \mathrm{hr}$. Then proteins were extracted from HUVECs with lysis buffer, separated by SDS-PAGE and transferred to nitrocellulose membranes as described previously [18]. Membranes were probed with antibodies raised against PAR-1 (Santa Cruz Biotechnology Inc., Delaware, CA, USA) or $\alpha$-tubulin (Santa Cruz Biotechnology Inc.), and then immune complexes were visualized with an enhanced chemiluminescence detection system (Amersham Bioscience, Buckinghamshire, United Kingdom).

\section{Statistical analysis}

All values were presented as means \pm standard error. Student's $t$-test or one-way analysis of variance followed Tukey's test was performed for statistical comparisons; $\mathrm{p}<0.05$ was considered significant. All statistical analyses were performed with the use of the PASW Statistics system (version 18.0; IBM Corporation, New York, NY, USA).

\section{Results}

We first examined the effects of rivaroxaban on citrated plasma-evoked superoxide generation in HUVECs. As shown in Figure 1A, rivaroxaban dose-dependently decreased the plasma-elicited ROS generation in HUVECs. Rivaroxaban itself did not affect the ROS generation in
HUVECs. Furthermore, AGEs potentiated the plasmainduced ROS generation in HUVECs, which was also significantly inhibited by the treatment with rivaroxaban. An inhibitor of NADPH oxidase, DPI was found to inhibit the $3 \%$ citrated human plasma-induced ROS generation in HUVECs (Figure 1B).

We next studied whether plasma could up-regulate RAGE gene expression in HUVECs. As shown in Figure 2, plasma increased RAGE mRNA levels in HUVECs, which was suppressed by rivaroxaban. Moreover, AGEs further increased RAGE mRNA levels in plasma-exposed HUVEC, which was also blocked by rivaroxaban.

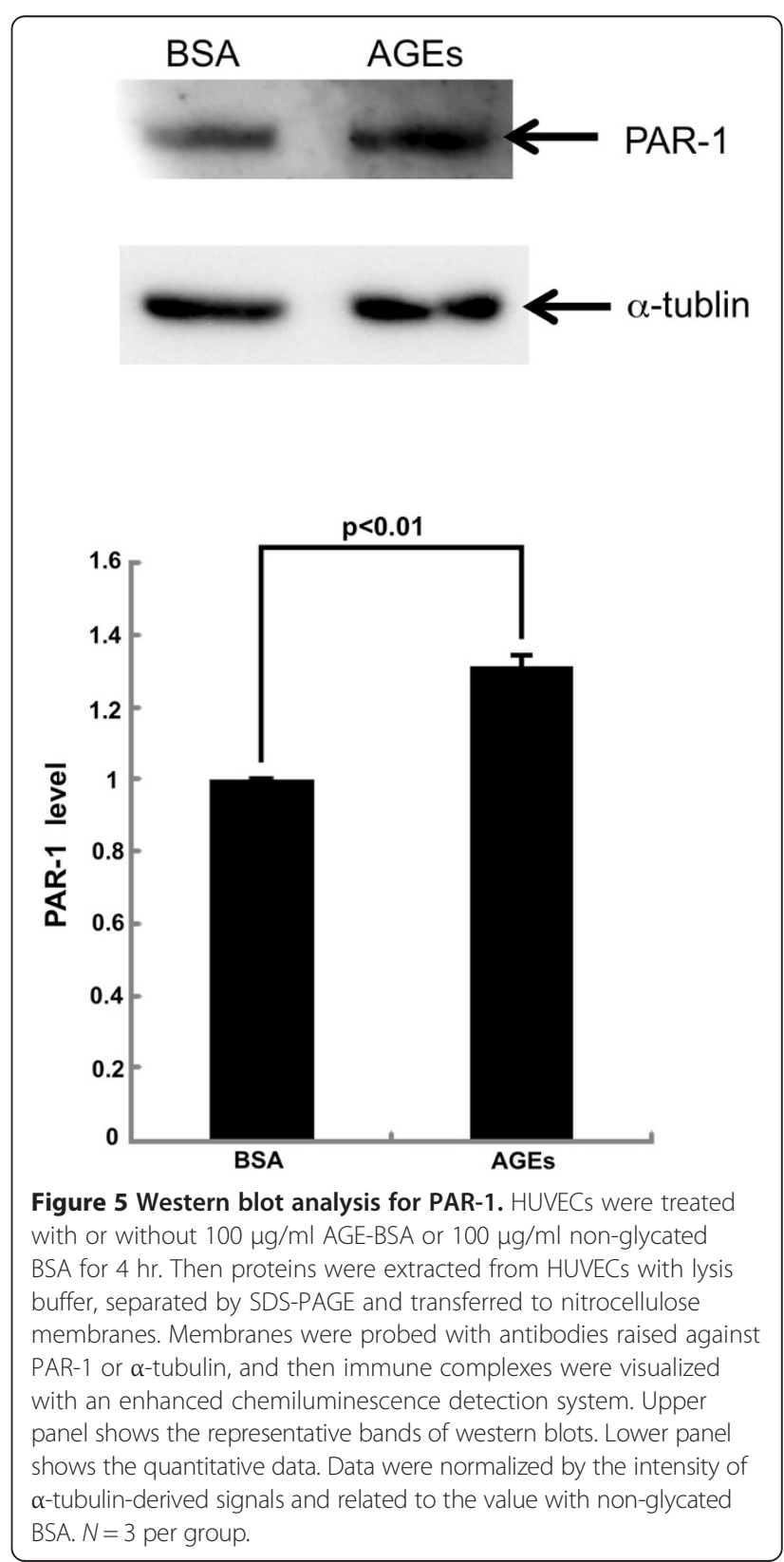


As the case in RAGE gene expression, rivaroxaban significantly inhibited the plasma-induced up-regulation of MCP-1 and ICAM-1 mRNA levels in HUVECs (Figure 3). These mRNA levels were further increased by the treatment with AGEs, both of which were significantly suppressed by rivaroxaban.

We investigated how plasma induced the ROS generation and subsequently evoked the inflammatory reactions in HUVECs. As shown in Figure 4A, a blocker of PAR-1, FR171113 completely inhibited the plasma-induced ROS generation in HUVECs. Moreover, FR171113 significantly prevented the plasma-elicited up-regulation of RAGE, MCP-1 and ICAM-1 mRNA levels in HUVECs (Figure 4BD). We further studied whether rivaroxaban could inhibit the plasma-evoked THP-1 cell adhesion to HUVECs. As shown in Figure 4E, 3\% citrated human plasma increased THP-1 cell adhesion to HUVECs by about 1.4-fold. Thirty $\mathrm{nM}$ rivaroxaban significantly inhibited the THP-1 cell adhesion to plasma-exposed HUVECs.

In addition, AGEs significantly increased the PAR-1 protein levels in HUVECs; PAR-1 levels were increased to 1.3-fold of that of non-glycated BSA-treated HUVECs (Figure 5).

\section{Discussion}

\section{Citrated plasma-evoked EC injury}

We chose the condition of $100 \mu \mathrm{g} / \mathrm{ml}$ AGE-BSA for $4 \mathrm{hr}$ in the present experiments because we have previously found that ROS generation and inflammatory reactions of ECs reach a maximum at $4 \mathrm{~h}$ in the presence of $100 \mu \mathrm{g} / \mathrm{ml} \mathrm{AGE-BSA} \mathrm{[16,19].} \mathrm{In} \mathrm{this} \mathrm{study,} \mathrm{we} \mathrm{found}$ for the first time that 3\% citrated plasma increased ROS generation, up-regulated RAGE, MCP-1 and ICAM1 mRNA levels in, and stimulated THP-1 cell adhesion to,
HUVECs, all of which were significantly blocked by the treatment with rivaroxaban, an inhibitor of Xa (Figures 1, 2, 3 and 4). Furthermore, 3\% citrated human plasma-evoked ROS generation, RAGE, MCP-1 and ICAM-1 gene induction was significantly blocked by the treatment with a blocker of PAR-1, FR171113 (Figure 4). Since calcium level in HUVEC basal medium used here $(6.4 \mathrm{mg} / \mathrm{dl})$ is almost equal to that of human serum, citrated plasma is recalcified and thrombin could be generated in the cell culture medium. Therefore, rivaroxaban could inhibit the formation of thrombin from prothrombin via blockade of Xa, thereby suppressing the thrombin-PAR-1-induced ROS generation in HUVECs (Figure 6). In the present study, we also found that an inhibitor of NADPH oxidase, DPI suppressed the plasma-induced ROS generation in HUVECs. So, re-calcified citrated plasma might evoke the ROS generation in HUVECs through he activation of NADPH oxidase via the interaction of thrombin with PAR-1. NADPH oxidase was shown to be necessary for thrombin-induced signaling pathway in vascular cells, thus supporting our speculation [20].

There is accumulating evidence that thrombin could elict the EC activation via PAR-1 [21-23]. Indeed, thrombin-PAR-1 interaction has induced MCP-1 and ICAM-1 expression in HUVECs [21-23]. We have previously shown that gene expression of MCP-1 and ICAM1 in ECs is induced by ROS generation via the activation of nuclear factor-kB (NF-kB) [24-29]. Moreover, thrombin has been shown to induce the MCP-1 and ICAM-1 gene expression in HUVECs via NF-kB [30-33]. So, the present findings suggest that recalcified plasma may stimulate MCP-1 and ICAM-1 mRNA levels in HUVECs through transcriptional activation of redox-sensitive transcriptional factor NF- $\mathrm{kB}$.

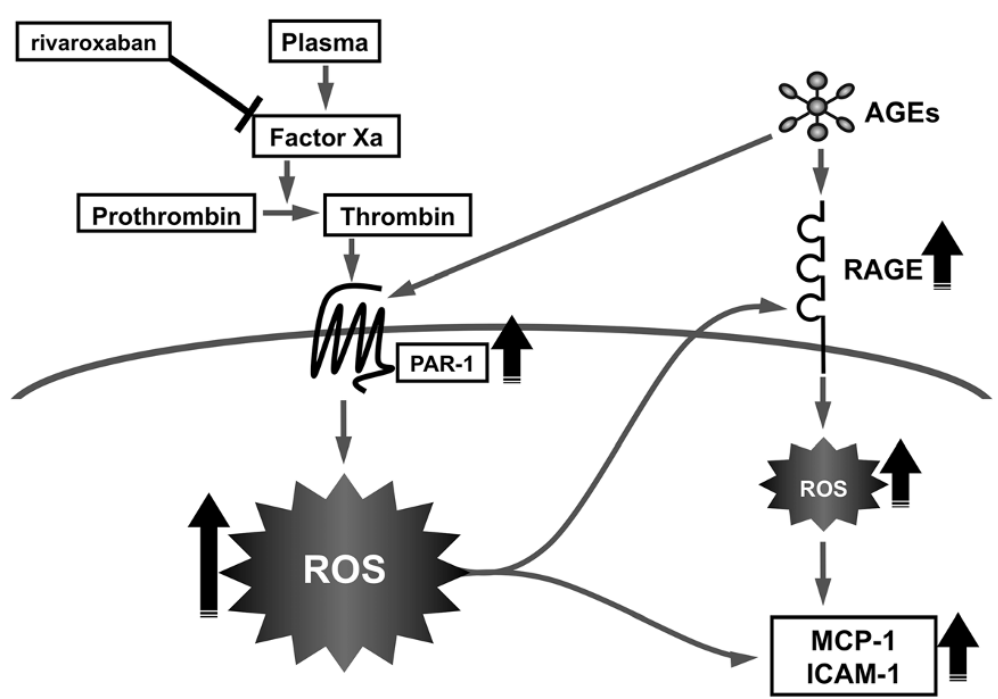

Figure 6 Possible participation of the AGE-RAGE axis in thrombin-evoked EC injury. 
Crosstalk between the AGE-RAGE axis and coagulation system Risks for various thromboembolic disorders are high in diabetes [10-13]. In the present study, we found that AGEs potentiated the $3 \%$ citrated human plasma-evoked ROS generation, RAGE, MCP-1 and ICAM-1 gene expression in HUVECs (Figures 1, 2 and 3). Further, PAR-1 expression was significantly induced by the treatment with AGEs (Figure 5). These observations suggest that AGEs could enhance the plasma-evoked thrombin signaling pathways in HUVECs via enhancement of PAR-1 expression. So, rivaroxaban might block the deleterious effects of AGEs on HUVECs by reducing the thrombin formation and subsequently suppressing the thrombin-PAR-1 axis. In this study, recalcified plasma induced ROS generation and RAGE gene induction, which could further potentiate the AGE-signaling pathways in HUVECs again. Since rivaroxaban inhibited the plasma-elicited ROS generation and RAGE gene expression in HUVECs, our present study suggests that blockade of the pathological crosstalk between the AGE-RAGE axis and thrombin-PAR-1 system by rivaroxaban might be a novel therapeutic strategy for reducing the risk of thromboembolic disorders in patients with diabetes [34].

AGE-RAGE axis has been reported to mediate atrial structural remodeling in the diabetic rats, thus increasing the risk of atrial fibrillation (AF) in diabetes [35]. Furthermore, recently, both plasma levels of AGEs and soluble RAGE, a marker of RAGE activation were shown to be higher in patients with AF, positively correlated with atrial dimensions, thus indicating a pathological role for the AGE-RAGE axis in the arrhythmogenic atrial structural remodeling in humans [36]. These findings further support the clinical relevance of suppression of the AGE-RAGE axis for the prevention of AF. The peak plasma concentration of rivaroxaban after administration of single oral dose of $10 \mathrm{mg}$ is reported to be about 300-400 nM [37]. So, the concentration of rivaroxaban having beneficial effects on HUVECs used in the present experiments (30-300 $\mathrm{nM}$ ) may also be comparable to the therapeutic level which is achieved in the treatment for patients with AF.

\section{Limitations}

In this study, in vitro-modified AGEs were prepared by incubating BSA with glyceraldehyde for 1 week; this process produced relatively highly-modified proteins in comparison to those in vivo. However, it was unlikely that extensivelymodified, unphysiologic AGEs that were formed under the in vitro-conditions may exert non-specific effects on HUVECs because we have previously found that immunological epitope of glyceraldehyde-modified AGEs is actually present in serum of diabetic patients and that the concentration $(100 \mu \mathrm{g} / \mathrm{ml})$ of in vitro-prepared AGEs used here are comparable with those of the in vivo diabetic situation [38].
An in vivo-animal model is needed to evaluate the in vitro-findings of rivaroxaban observed here. Inhibition of RAGE may help to demonstrate the relation between the AGE-RAGE axis and thrombin-PAR-1 system. In addition, further clinical intervention trials are also needed to clarify whether blockade of the crosstalk between the AGE-RAGE axis and thrombin-PAR-1 axis could actually decrease the risk of thromboembolic disorders and slow the progression of atherosclerosis in patients with AF, especially in diabetic subjects. Lastly, we have to mention about the adverse effects of rivaroxaban, i.e., more bleeding, if it is widely used especially for high-risk patients.

\section{Conclusions}

Our present observations suggest citrated plasma could induce oxidative and inflammatory reactions in ECs via the activation of thrombin-PAR-1 system, which was potentiated by AGEs. Blockade of the crosstalk between AGE-RAGE axis and coagulation system might be a novel therapeutic target for thromboembolic disorders in diabetes (Figure 6).

\section{Abbreviations}

AGEs: Advanced glycation end products; RAGE: Receptor for AGEs; ECs: Endothelial cells; PAR-1: Protease-activated receptor-1; ROS: Reactive oxygen species; MCP-1: Monocyte chemoattractant protein-1; ICAM-1: Intercellular adhesion molecule-1; HUVECS: Human umbilical vein ECs; BSA: Bovine serum albumin; DPI: Diphenylene iodonium; DHE: Dihydroethidium; RT-PCR: Reverse transcription-polymerase chain reaction; NF-kB: Nuclear factor-kB; AF: Atrial fibrillation.

\section{Competing interests}

This project was financially supported by Bayer AG. Dr. Yamagishi, Dr. Ueda and Dr. Fukami have received honoraria such as lecture fees from Bayer AG.

\section{Authors' contributions}

YI, TM, SU and KF acquired and interpreted data. SY mainly contributed to the present study, conceptualized and designed the study, acquired, analyzed, and interpreted data, and drafted the manuscript, and took responsibility for the integrity of the data and the accuracy of the data analysis. All authors read and approved the final manuscript.

\section{Acknowledgments}

This study was supported in part by Grants-in-Aid for Scientific Research (B) from the Ministry of Education, Culture, Sports, Science and Technology, Japan (to S.Y.), and by MEXT-Supported Program for the Strategic Research Foundation at Private Universities, the Ministry of Education, Culture, Sports, Science and Technology (MEXT) (to S.Y.).

\section{Author details}

${ }^{1}$ Department of Pathophysiology and Therapeutics of Diabetic Vascular Complications, Kurume University School of Medicine, 67 Asahi-machi, Kurume 830-0011, Japan. ${ }^{2}$ Department of Medicine, Kurume University School of Medicine, Kurume 830-0011, Japan.

Received: 12 December 2013 Accepted: 8 March 2014

Published: 13 March 2014

\section{References}

1. Vlassara H, Bucala R: Recent progress in advanced glycation and diabetic vascular disease: role of advanced glycation end product receptors. Diabetes 1996, 45(Suppl 3):S65-66.

2. Brownlee $M$, Cerami A, Vlassara H: Advanced glycosylation end products in tissue and the biochemical basis of diabetic complications. N Engl J Med 1988, 318:1315-1321. 
3. Rahbar S: Novel inhibitors of glycation and AGE formation. Cell Biochem Biophys 2007, 48:147-157.

4. Yamamoto Y, Kato I, Doi T, Yonekura H, Ohashi S, Takeuchi M, Watanabe T, Yamagishi S, Sakurai S, Takasawa S, Okamoto H, Yamamoto H: Development and prevention of advanced diabetic nephropathy in RAGE-overexpressing mice. J Clin Invest 2001, 108:261-268.

5. Wendt TM, Tanji N, Guo J, Kislinger TR, Qu W, Lu Y, Bucciarelli LG, Rong LL, Moser B, Markowitz GS, Stein G, Bierhaus A, Liliensiek B, Arnold B, Nawroth PP, Stern DM, D'Agati VD, Schmidt AM: RAGE drives the development of glomerulosclerosis and implicates podocyte activation in the pathogenesis of diabetic nephropathy. Am J Pathol 2003, 162:1123-1137.

6. Yamagishi S, Imaizumi T: Diabetic vascular complications: pathophysiology, biochemical basis and potential therapeutic strategy. Curr Pharm Des 2005, 11:2279-2299.

7. Yamagishi S, Nakamura K, Matsui T, Noda Y, Imaizumi T: Receptor for advanced glycation end products (RAGE): a novel therapeutic target for diabetic vascular complication. Curr Pharm Des 2008, 14:487-495.

8. Jandeleit-Dahm K, Cooper ME: The role of AGEs in cardiovascular disease. Curr Pharm Des 2008, 14:979-986.

9. Tahara N, Yamagishi S, Takeuchi M, Honda A, Tahara A, Nitta Y, Kodama N, Mizoguchi M, Kaida H, Ishibashi M, Hayabuchi N, Matsui T, Imaizumi T: Positive association between serum level of glyceraldehyde-derived advanced glycation end products and vascular inflammation evaluated by [(18)F]fluorodeoxyglucose positron emission tomography. Diabetes Care 2012, 35:2618-2625

10. Takenaka K, Yamagishi S, Matsui T, Nakamura K, Imaizumi T: Role of advanced glycation end products (AGEs) in thrombogenic abnormalities in diabetes. Curr Neurovasc Res 2006, 3:73-77.

11. Alzahrani SH, Ajjan RA: Coagulation and fibrinolysis in diabetes. Diab VasC Dis Res 2010, 7:260-273.

12. Piazza G, Goldhaber SZ, Kroll A, Goldberg R, Emery C, Spencer FA: Venous thromboembolism in patients with diabetes mellitus. Am J Med 2012, 125:709-716.

13. Klem I, Wehinger C, Schneider B, Hartl E, Finsterer J, Stöllberger C: Diabetic atrial fibrillation patients: mortality and risk for stroke or embolism during a 10-year follow-up. Diabetes Metab Res Rev 2003, 19:320-328.

14. Yamagishi S, Fujimori $\mathrm{H}$, Yonekura $\mathrm{H}$, Yamamoto $\mathrm{Y}$, Yamamoto $\mathrm{H}$ : Advanced glycation endproducts inhibit prostacyclin production and induce plasminogen activator inhibitor-1 in human microvascular endothelial cells. Diabetologia 1998, 41:1435-1441.

15. Bierhaus A, IIImer T, Kasper $M$, Luther $T$, Quehenberger $P$, Tritschler $H$, Wahl $P$, Ziegler R, Müller M, Nawroth PP: Advanced glycation end product (AGE)-mediated induction of tissue factor in cultured endothelial cells is dependent on RAGE. Circulation 1997, 96:2262-2271.

16. Yamagishi $S$, Nakamura $K$, Matsui T, Inagaki $Y$, Takenaka $K$, Jinnouchi $Y$, Yoshida $Y$, Matsuura T, Narama I, Motomiya Y, Takeuchi M, Inoue H, Yoshimura A, Bucala R, Imaizumi T: Pigment epithelium-derived factor inhibits advanced glycation end product-induced retinal vascular hyperpermeability by blocking reactive oxygen species-mediated vascular endothelial growth factor expression. J Biol Chem 2006, 281:20213-20220.

17. Yamagishi S, Kikuchi S, Nakamura K, Matsui T, Makino T, Norisugi O, Shimizu T, Inoue $\mathrm{H}$, Imaizumi T: Pigment epithelium-derived factor (PEDF) blocks angiotensin II-induced T cell adhesion to endothelial cells by suppressing intercellular adhesion molecule-1. Horm Metab Res 2006, 38:546-548.

18. Ojima A, Ishibashi Y, Matsui T, Maeda S, Nishino Y, Takeuchi M, Fukami K, Yamagishi S: Glucagon-like peptide-1 receptor agonist inhibits asymmetric dimethylarginine generation in the kidney of streptozotocin-induced diabetic rats by blocking advanced glycation end product-induced protein arginine methyltranferase-1 expression. Am J Pathol 2013, 182:132-141.

19. Si Y, Yonekura H, Yamamoto Y, Katsuno K, Sato F, Mita I, Ooka H, Satozawa $\mathrm{N}$, Kawakami T, Nomura M, Yamamoto H: Advanced glycation end products-driven angiogenesis in vitro. Induction of the growth and tube formation of human microvascular endothelial cells through autocrine vascular endothelial growth factor. J Biol Chem 1997, 272:8723-8730.

20. Du J, Brink M, Peng T, Mottironi B, Delafontaine $P$ : Thrombin regulates insulinlike growth factor-1 receptor transcription in vascular smooth muscle: characterization of the signaling pathway. Circ Res 2001, 88:1044-1052.

21. Wei HJ, Li YH, Shi GY, Liu SL, Chang PC, Kuo CH, Wu HL: Thrombomodulin domains attenuate atherosclerosis by inhibiting thrombin-induced endothelial cell activation. Cardiovasc Res 2011, 92:317-327.

22. Delekta PC, Apel IJ, Gu S, Siu K, Hattori Y, McAllister-Lucas LM, Lucas PC: Thrombin-dependent NF-\{kappa\}B activation and monocyte/endothelial adhesion are mediated by the CARMA3 $\cdot$ Bcl10 $\cdot$ MALT1 signalosome. J Biol Chem 2010, 285:41432-41442.

23. Lin Z, Hamik A, Jain R, Kumar A, Jain MK: Kruppel-like factor 2 inhibits protease activated receptor-1 expression and thrombin-mediated endothelial activation. Arterioscler Thromb Vasc Biol 2006, 26:1185-1189.

24. Yamagishi S, Nakamura K, Ueda S, Kato S, Imaizumi T: Pigment epitheliumderived factor (PEDF) blocks angiotensin II signaling in endothelial cells via suppression of NADPH oxidase: a novel anti-oxidative mechanism of PEDF. Cell Tissue Res 2005, 320:437-445.

25. Yamagishi S, Inagaki Y, Kikuchi S: Nifedipine inhibits tumor necrosis factoralpha-induced monocyte chemoattractant protein-1 overexpression by blocking NADPH oxidase-mediated reactive oxygen species generation. Drugs Exp Clin Res 2003, 29:147-152.

26. Inagaki Y, Yamagishi S, Okamoto T, Takeuchi M, Amano S: Pigment epithelium-derived factor prevents advanced glycation end productsinduced monocyte chemoattractant protein-1 production in microvascular endothelial cells by suppressing intracellular reactive oxygen species generation. Diabetologia 2003, 46:284-287.

27. Yamagishi S, Matsui T, Nakamura K, Inoue H, Takeuchi M, Ueda S, Okuda S, Imaizumi T: Olmesartan blocks inflammatory reactions in endothelial cells evoked by advanced glycation end products by suppressing generation of reactive oxygen species. Ophthalmic Res 2008, 40:10-15.

28. Ishibashi Y, Matsui T, Maeda S, Higashimoto Y, Yamagishi S: Advanced glycation end products evoke endothelial cell damage by stimulating soluble dipeptidyl peptidase-4 production and its interaction with mannose 6-phosphate/insulinlike growth factor II receptor. Cardiovasc Diabetol 2013, 12:125.

29. Yamagishi S, Matsui T, Nakamura K, Takeuchi M, Inoue H: Telmisartan inhibits advanced glycation end products (AGEs)-elicited endothelial cell injury by suppressing AGE receptor (RAGE) expression via peroxisome proliferatoractivated receptor-gammaactivation. Protein Pept Lett 2008, 15:850-853.

30. Kawanami D, Matoba K, Kanazawa Y, Ishizawa S, Yokota T, Utsunomiya K: Thrombin induces MCP-1 expression through Rho-kinase and subsequent p38MAPK/NF-KB signaling pathway activation in vascular endothelial cells. Biochem Biophys Res Commun 2011, 411:798-803.

31. Xue J, Thippegowda PB, Hu G, Bachmaier K, Christman JW, Malik AB, Tiruppathi C: NF-kappaB regulates thrombin-induced ICAM-1 gene expression in cooperation with NFAT by binding to the intronic NF-kappaB site in the ICAM-1 gene. Physiol Genomics 2009, 38:42-53.

32. Miho N, Ishida T, Kuwaba N, Ishida M, Shimote-Abe K, Tabuchi K, Oshima T, Yoshizumi M, Chayama K: Role of the JNK pathway in thrombin-induced ICAM-1 expression in endothelial cells. Cardiovasc Res 2005, 68:289-298.

33. Minhajuddin M, Fazal F, Bijli KM, Amin MR, Rahman A: Inhibition of mammalian target of rapamycin potentiates thrombin-induced intercellular adhesion molecule-1 expression by accelerating and stabilizing NF-kappa B activation in endothelial cells. J Immuno/ 2005, 174:5823-5829.

34. Fukushima Y, Daida H, Morimoto T, Kasai T, Miyauchi K, Yamagishi S, Takeuchi M, Hiro T, Kimura T, Nakagawa Y, Yamagishi M, Ozaki Y, Matsuzaki M, JAPAN-ACS Investigators: Relationship between advanced glycation end products and plaque progression in patients with acute coronary syndrome: the JAPAN-ACS sub-study. Cardiovasc Diabetol 2013, 12:5.

35. Kato T, Yamashita T, Sekiguchi A, Tsuneda T, Sagara K, Takamura M, Kaneko S, Aizawa T, Fu LT: AGEs-RAGE system mediates atrial structural remodeling in the diabetic rat. J Cardiovasc Electrophysiol 2008, 19:415-420.

36. Raposeiras-Roubín S, Rodiño-Janeiro BK, Grigorian-Shamagian L, SeoaneBlanco A, Moure-González M, Varela-Román A, Álvarez E, González-Juanatey $J R$ : Evidence for a role of advanced glycation end products in atrial fibrillation. Int J Cardiol 2012, 157:397-402.

37. Kubitza D, Becka M, Roth A, Mueck W: The influence of age and gender on the pharmacokinetics and pharmacodynamics of rivaroxaban-an oral, direct Factor Xa inhibitor. J Clin Pharmacol 2013, 53:249-255.

38. Takeuchi M, Makita Z, Bucala R, Suzuki T, Koike T, Kameda Y: Immunological evidence that non-carboxymethyllysine advanced glycation end-products are produced from short chain sugars and dicarbonyl compounds in vivo. Mol Med 2000, 6:114-125.

\section{doi:10.1186/1475-2840-13-60}

Cite this article as: Ishibashi et al:: Advanced glycation end products potentiate citrated plasma-evoked oxidative and inflammatory reactions in endothelial cells by up-regulating protease-activated receptor-1 expression. Cardiovascular Diabetology 2014 13:60. 